\title{
Association between sleep quality and central obesity among southern Chinese reproductive-aged women
}

\section{Bingbing Li}

Henan University

Nan Liu

Henan University

Donghui Guo

The People's Hospital of Longhua.Shenzhen

Bo Li

Henan University

Yan Liang

Xuzhou Medical University

Lingling Huang

Shanghai Lida University

Xiaoxiao Wang

Tongji Hospital of Tongji Medical College of Huazhong University of Science and Technology

Zhenzhen Su

Henan University

Guozeng Zhang

Henan University

Peixi Wang ( $\sim$ peixi001@163.com)

Henan University

Research article

Keywords: sleep quality, central obesity, reproductive-aged women, Pittsburgh Sleep Quality Index, Chinese

Posted Date: March 3rd, 2020

DOI: https://doi.org/10.21203/rs.3.rs-15728/v1

License: (c) (1) This work is licensed under a Creative Commons Attribution 4.0 International License.

Read Full License 
Version of Record: A version of this preprint was published at BMC Women's Health on August 4th, 2021. See the published version at https://doi.org/10.1186/s12905-021-01407-0. 


\section{Abstract}

Background Females are more prone to complain about sleep problems. Poor sleep quality in this group may make them more vulnerable to suffering obesity and other diseases, which can seriously affect their fitness and quality of life. Nevertheless, the connections between sleep quality and central obesity among reproductive-aged women are not clear. The aims of this study were to explore the association between sleep quality as measured by the Pittsburgh Sleep Quality Index (PSQI) and central obesity among Chinese reproductive-aged women and to identify the independent contributions of sociodemographic characteristics, health-related factors, and sleep quality to central obesity.

Methods In this cross-sectional survey, 2449 Chinese reproductive-aged women aged 18-49 years were studied. Sleep quality was assessed using the Chinese version of the PSQI. Central obesity as the outcome of interest was a binary variable; women were categorized as with versus without central obesity. Clustered logistic regression was used to analyze the independent contribution of sleep quality to central obesity.

Results The risk of central obesity increased significantly with poor sleep quality (assessed by global PSQI score) (adjusted OR(Odds Ratio) $=2.20$ per SD increase; $P=0.004)$, increased sleep disturbance score (adjusted $\mathrm{OR}=1.11$ per $\mathrm{SD}$ increase; $\mathrm{P}=0.042$ ) and decreased subjective sleep quality score (adjusted $\mathrm{OR}=0.81$ per $\mathrm{SD}$ increase; $\mathrm{P}<0.001)$. The independent contribution of sleep quality was $9.9 \%$, less than those of sociodemographic (73.3\%) and health-related (16.8\%) variables. Among complaints related to sleep disturbance, the inability to breathe comfortably and having bad dreams showed significant associations with central obesity.

Conclusions There exists some degree of correlation between sleep quality and central obesity among Chinese reproductive-aged women. Understanding this link has public health relevance because of the important role sleep plays in health. It also has some implications for the discovery of novel strategies to prevent central obesity and the implementation of weight maintenance programs in this population group.

\section{Background}

Obesity is a global public health issue estimated to be majorly responsible for increased mortality from cardiovascular diseases and cancers [1,2]. Moreover, obesity (especially central obesity) is reported to be correlated with insulin resistance, which is recognized as a crucial risk factor for the development and progression of metabolic syndrome (MetS) [3]. It is necessary to understand the innumerable factors that could exert an effect on the occurrence and development of obesity.

Currently, sleep is considered as a major role to maintain health. Sleep restriction can result in impaired metabolism and endocrine function [4, 5]. Short or long sleep duration and poor sleep quality have been reported to be correlated with both general and central obesity [6-8]. However, the association of sleep including duration and quality with obesity are not consistent $[9,10]$. 
It is noteworthy that most conclusions on the sleep-obesity relationship were derived from studies by using body mass index (BMI) as the main indicator of obesity. BMI, as an adiposity index, is generally used to reflect the extent of peripheral obesity; nevertheless, another obesity type: central obesity is ignored. As numerous studies have verified, central obesity is strongly correlated with the development of various obesity-related chronic diseases and is better reflected by measuring waist circumference (WC) [11-13]. Recent analyses demonstrated that the prevalence trend of central obesity is continuing to escalate worldwide including China $[14,15]$. Hence, determining the underlying causes as well as potentially modifiable risk factors is crucial to better inform prevention program design and decrease the growth rate of central obesity.

Females are more prone to complain about sleep problems than males [16]. Poor sleep quality in this group may make them more vulnerable to suffering obesity and other diseases, which can seriously affect their fitness and quality of life; furthermore, reproduction might be also affected. Nevertheless, the connection between sleep quality and central obesity of Chinese reproductive-aged women are not clear. Therefore, the aim of this study is using clustered logistic regression to analyze potential associations between sleep quality (measured by the PSQI) and central obesity (as determined by WC) and to identify the independent contribution of sleep quality to central obesity in Chinese reproductive women aged 1849 years. By analyzing these associations, it may enhance our knowledge concerning the relationship between sleep quality and central obesity of Chinese reproductive-aged females. In addition, it may be a support for the discovery of novel strategies to prevent central obesity and promote health of this population group.

\section{Methods}

\section{Participants}

This cross-sectional health survey was conducted in a district of the Pearl River Delta region of China in 2018 , through face-to-face interview at participants' residences. The central obesity rate of women was at $35.0 \%$ in our pre-survey in the area; with a maximal tolerance at $2.0 \%$ and error of type $\nabla$ at $5 \%$, the minimal sample sizes were 2185 reproductive-aged females. Considering $10 \%$ invalid sample size, at least 2404 reproductive-aged women with the age of 18-49 years were needed; we selected 2513 subjects by sample random sampling. Participants with history of sleep-related breathing disorders (e.g., sleep apnea hypopnea syndrome, SAHS, obesity hypoventilation syndrome, OHS, and others), restless legs syndrome, depression, psychiatric disorders, cancer, ovariectomy, postmenopause, estrogen therapy, and others were excluded. Finally, 2449 of them were included in our analysis. Written informed consent was obtained from each study participant. The People's Hospital of Longhua.Shenzhen Medical Ethics Committee approved the study (2917055).

\section{Measurement Of Sleep Quality}


A translated version of the PSQI was used to assess sleep quality. It was a standardized self-report 19item questionnaire designed to collect the subjective nature of one's sleep habit over a one-month period [17]. Each item with a four-point scale ranges from 0 to 3 . In many settings, the PSQI has been used in diagnosing sleep disorders and proven to have a good reliability and validity [18-20]. It estimates several different aspects of sleep, which reflect seven aspects of sleep problems, including subjective sleep quality, sleep latency, sleep duration, habitual sleep efficiency, sleep disturbance, use of sleep medication, and daytime dysfunction [17]. Their sum constitutes the global sleep quality score (ranging from 0 to 21), with a higher score indicating worse sleep quality. A global PSQI score above seven differentiates poor from good sleepers, with a high diagnostic sensitivity and specificity ( $98.3 \%$ and $90.2 \%$, respectively) in Chinese population [21].

\section{General Research Questionnaire}

The questionnaire included the following variables: sociodemographic characteristics (age group, marital status, educational level, and occupational status), health-related factors (smoking, drinking, exercise, hypertension, diabetes mellitus, two-week morbidity, and hospitalization in the last year), and sleep quality (assessed by the PSQI). The definition of smoking was having smoked more than 100 cigarettes in their life-time. The definition of drinking was having consumed alcohol of more than $30 \mathrm{~g} /$ week within the last 12 months. Exercise was categorized into three statuses. Self-reported information on doctordiagnosed hypertension/diabetes mellitus, two-week morbidity, and hospitalized in the last year was obtained. Central obesity was measured by WC. Qualified examiners obtained the WC (to the nearest $0.1 \mathrm{~cm}$ ) by duplicate measuring the midpoint between the edge of the lower rib and the iliac crest and averaged the values [22]. Central obesity was defined according to the recommendations of the International Diabetes Federation definition of MetS as WC $\geq 80 \mathrm{~cm}$ in women [23].

\section{Statistical analysis}

Data analyses were performed using SPSS 18.0 (SPSS, Inc., Chicago, IL, USA). Descriptive statistics were used to summarize participant characteristics. Comparison between groups in univariate analyses was performed by the independent-samples t-test and $\chi^{2}$ test. Multivariate analysis was performed by using clustered logistic regression analyses (forward stepwise method), where central obesity was considered as the dependent variable and sociodemographic characteristics, health-related factors, and sleep quality were independent variables. A two-sided 0.05 statistical significance level was set for all analyses. During the regression analysis, PSQI component scores as continuous variables were standardized for better comparison.

Specifically, the independent contributions of sociodemographic characteristics, health-related variables, and sleep quality to central obesity were assessed using clustered multiple logistic regression analyses $[24,25]$. There was the possibility of multi-directional links between the three clusters and the dependent variable as shown in Fig. 1. Cluster 1 could have affected Clusters 2 and 3 as well as the dependent 
variable. Similarly, Cluster 2 might have affected Cluster 3 and the dependent variable. However, Cluster 3 might only have influenced the dependent variable. Consequently, variables in the prior cluster might have an impact on variables in the subsequent cluster [24]. We determined the final regression model in three phases, the details were shown in previous studies [24].

The independent effect of each cluster was derived from the corresponding $\mathrm{R}^{2}$ change, which resembled the classical $R^{2}$ applied to linear regression models [25]. Then the formula (individual $R^{2}$ change/total $R^{2}$ $\times 100 \%)$ was used to calculate the independent contribution of each cluster [25].

\section{Results}

\section{Characteristics of participants}

A total number of 2449 of women were participated in this survey. The average age was $33.0 \pm 7.5$ (SD), with roughly $32.4 \%$ reproductive-aged women with central obesity. Most participants were married (81.9\%), employed (79.2\%) and have completed high school or higher education (78.4\%). As increasing by age, there was a higher prevalence of central obesity $(P<0.001)$. Also, the prevalence of hypertension $(P<0.001)$, diabetes mellitus $(P=0.005)$ and hospitalization in the last year $(P<0.001)$ was significantly related with central obesity in women. Scores of seven PSQI components were described as mean + SD, varying from $0.02 \pm 0.17$ to $0.55 \pm 0.66$, in which the mean component score of use of sleep medication was the lowest, while the component of sleep latency was scored the highest. More details of participants' characteristics are presented in Table 1. 
Table 1

Characteristics of the study population according to central obesity

\begin{tabular}{|c|c|c|c|c|}
\hline \multirow[t]{2}{*}{ Variable } & \multirow{2}{*}{$\begin{array}{l}\text { Total } \\
(\mathrm{N}=2449)\end{array}$} & \multicolumn{2}{|l|}{ Central obesity } & \multirow[t]{2}{*}{$P$ Value } \\
\hline & & Yes $(n=794)$ & No $(n=1655)$ & \\
\hline \multicolumn{5}{|c|}{ Cluster 1: Sociodemographic } \\
\hline Age group(years) & & & & $<0.001$ \\
\hline $18-25$ & $380(15.5)$ & $57(15.0)$ & $323(85.0)$ & \\
\hline $26-35$ & $1217(49.7)$ & $397(32.6)$ & $820(67.4)$ & \\
\hline $36-45$ & $674(27.5)$ & 261(38.7) & $413(61.3)$ & \\
\hline $46-49$ & 178(7.3) & $79(44.4)$ & $99(55.6)$ & \\
\hline Marital status & & & & $<0.001$ \\
\hline Unmarried & $403(16.5)$ & $61(15.1)$ & $342(84.9)$ & \\
\hline Married & 2005(81.9) & $720(35.9)$ & 1285(64.1) & \\
\hline Widowed & $9(0.4)$ & $1(11.1)$ & $8(88.9)$ & \\
\hline Divorced & $32(1.2)$ & 12(37.5) & $20(62.5)$ & \\
\hline Educational level & & & & $<0.001$ \\
\hline Primary school or lower & $86(3.5)$ & $47(54.7)$ & $39(45.3)$ & \\
\hline Middle school & 444(18.1) & $170(38.3)$ & $274(61.7)$ & \\
\hline High school or above & 1919(78.4) & $577(30.1)$ & 1342(69.9) & \\
\hline Occupational status & & & & $<0.001$ \\
\hline Employed & $1940(79.2)$ & $598(30.8)$ & 1342(69.2) & \\
\hline Retired & $14(0.6)$ & $6(42.9)$ & $8(57.1)$ & \\
\hline Student & $89(3.6)$ & 15(16.9) & 74(83.1) & \\
\hline Unemployed & 406(16.6) & $175(43.1)$ & 231(56.9) & \\
\hline \multicolumn{5}{|l|}{ Cluster 2: Health-related } \\
\hline Smoking & & & & 0.498 \\
\hline Yes & $9(0.4)$ & $2(22.2)$ & $7(77.8)$ & \\
\hline No & 2440(99.6) & 792(32.5) & 1648(67.5) & \\
\hline
\end{tabular}

Note: $\mathrm{M}$, mean; SD, standard deviation. 


\begin{tabular}{|c|c|c|c|c|}
\hline Variable & Total & \multicolumn{2}{|c|}{ Central obesity } & P Value \\
\hline Yes & $13(0.5)$ & $7(53.8)$ & $6(46.2)$ & \\
\hline No & $2436(99.5)$ & $787(32.3)$ & $1649(67.7)$ & \\
\hline \multicolumn{4}{|l|}{ Exercise } & 0.802 \\
\hline Over 3 times/week & $824(33.6)$ & $260(31.6)$ & $564(68.4)$ & \\
\hline $1-2$ times/week & $794(32.4)$ & 262(33.0) & $532(67.0)$ & \\
\hline No exercise & $831(33.9)$ & $272(32.7)$ & $559(67.3)$ & \\
\hline \multicolumn{4}{|l|}{ Hypertension } & $<0.001$ \\
\hline Yes & $29(1.2)$ & $21(72.4)$ & $8(27.6)$ & \\
\hline No & $2420(98.8)$ & $773(31.9)$ & $1647(68.1)$ & \\
\hline \multicolumn{4}{|l|}{ Diabetes mellitus } & 0.005 \\
\hline Yes & $9(0.4)$ & $7(77.8)$ & $2(22.2)$ & \\
\hline No & $2440(99.6)$ & $787(32.3)$ & $1653(67.7)$ & \\
\hline \multicolumn{4}{|l|}{ 2-week morbidity } & 0.523 \\
\hline Yes & $66(2.7)$ & 19(28.8) & $47(71.2)$ & \\
\hline No & 2383(97.3) & $775(32.5)$ & $1608(67.5)$ & \\
\hline \multicolumn{4}{|l|}{ Hospitalization in the last year } & $<0.001$ \\
\hline Yes & 154(6.3) & $75(48.7)$ & $79(51.3)$ & \\
\hline No & 2295(93.7) & $719(31.3)$ & $1576(68.7)$ & \\
\hline \multicolumn{5}{|l|}{ Cluster 3: PSQI domain scores } \\
\hline \multicolumn{4}{|l|}{ Global PSQI score } & 0.005 \\
\hline$\leq 7$ & 2373(96.9) & $758(31.9)$ & $1615(68.1)$ & \\
\hline$>7$ & $76(3.1)$ & $36(47.4)$ & $40(52.6)$ & \\
\hline Subjective sleep quality; $M \pm S D$ & $0.42 \pm 0.60$ & $0.41 \pm 0.61$ & $0.43 \pm 0.59$ & 0.417 \\
\hline Sleep latency; $M \pm S D$ & $0.55 \pm 0.66$ & $0.55 \pm 0.68$ & $0.54 \pm 0.65$ & 0.716 \\
\hline Sleep duration; $M \pm S D$ & $0.38 \pm 0.52$ & $0.40 \pm 0.56$ & $0.37 \pm 0.50$ & 0.167 \\
\hline Habitual sleep efficiency; $M \pm S D$ & $0.15 \pm 0.47$ & $0.15 \pm 0.49$ & $0.14 \pm 0.46$ & 0.544 \\
\hline
\end{tabular}




\begin{tabular}{|lllll|}
\hline Variable & Total & Central obesity & P Value \\
\hline Sleep disturbance; $M \pm S D$ & $0.33 \pm 0.49$ & $0.37 \pm 0.52$ & $0.31 \pm 0.48$ & 0.008 \\
\hline Use of sleep medication; $\mathrm{M} \pm$ SD & $0.02 \pm 0.17$ & $0.03 \pm 0.21$ & $0.02 \pm 0.15$ & 0.217 \\
\hline Daytime dysfunction; $M \pm S D$ & $0.31 \pm 0.64$ & $0.32 \pm 0.68$ & $0.31 \pm 0.62$ & 0.609 \\
\hline Note: M, mean; SD, standard deviation. & & & \\
\hline
\end{tabular}

\section{Global and component PSQI scores and central obesity}

Poor sleep quality was significantly correlated with central obesity (crude odds ratio $(O R)=2.76 ; 95 \%$ confidence interval $(\mathrm{Cl})=1.49-5.14 ; \mathrm{P}=0.001)$ (Table 2 ). The risk of central obesity was significantly increased with the elevated component PSQI score in sleep disturbance (crude OR $=1.17 ; 95 \% \mathrm{Cl}=1.06-$ $1.29 ; \mathrm{P}=0.001$ ) and the decreased component $\mathrm{PSQ}$ I score in subjective sleep quality (crude $\mathrm{OR}=0.86$; $95 \% \mathrm{Cl}=0.77-0.96 ; \mathrm{P}=0.005)$.

Table 2

Associations between PSQI components and central obesity among females $(\mathrm{N}=2449)$

\begin{tabular}{|c|c|c|c|}
\hline PSQI components ${ }^{a}$ & $O^{b}$ & $95 \% \mathrm{Cl}$ & P Value \\
\hline Global PSQI score( $\leq 7)$ & 1 & Reference & \\
\hline$>7$ & 2.76 & $1.49-5.14$ & $0.001 \dagger$ \\
\hline Subjective sleep quality & 0.86 & $0.77-0.96$ & $0.005 t$ \\
\hline Sleep latency & 0.96 & $0.88-1.06$ & 0.46 \\
\hline Sleep duration & 1.60 & $0.97-1.16$ & 0.21 \\
\hline Habitual sleep efficiency & 0.95 & $0.86-1.05$ & 0.27 \\
\hline Sleep disturbance & 1.17 & $1.06-1.29$ & $0.001+$ \\
\hline Use of sleep medication & 1.05 & $0.97-1.14$ & 0.21 \\
\hline Daytime dysfunction & 0.96 & $0.86-1.06$ & 0.40 \\
\hline \multicolumn{4}{|c|}{$\begin{array}{l}\text { Note: }{ }^{\text {a }} \text { The seven sleep quality domains and global PSQI score (as a dichotomous variable) were } \\
\text { included as predictor variables for central obesity in a multivariate regression model without } \\
\text { adjustment for other variables. }\end{array}$} \\
\hline \multicolumn{4}{|c|}{ b Odds ratio per standard deviation increase in a predictor variable; $\mathrm{Cl}$, confidence interval. } \\
\hline$+P<0.05$ & & & \\
\hline
\end{tabular}




\section{Influential Factors Of Central Obesity}

In Cluster 1, age group, marital status, educational level, and occupational status were associated with central obesity (Table 3). Their independent contribution was 73.3\%. In Cluster 2, hypertension, diabetes mellitus, and hospitalization in the last year were positively associated with central obesity. Their independent contribution was $16.8 \%$. And also, in Cluster 3 , the risk of central obesity increased significantly with poor sleep quality (adjusted $\mathrm{OR}=2.20 ; 95 \% \mathrm{Cl}=1.28-3.78 ; \mathrm{P}=0.004$ ), increased sleep disturbance score (adjusted OR $=1.11 ; 95 \% \mathrm{Cl}=1.01-1.22 ; \mathrm{P}=0.042$ ), and decreased subjective sleep quality score (adjusted $\mathrm{OR}=0.81 ; 95 \% \mathrm{Cl}=0.73-0.90 ; \mathrm{P}<0.001$ ). The independent contribution of the third cluster to central obesity was $9.9 \%$. Moreover, associations between complaints of sleep disturbances and central obesity were further analyzed and illustrated in Fig. 2. Among the symptoms of sleep disturbances, the inability to breathe comfortably and having bad dreams showed significant associations with central obesity. Participants who were unable to breathe comfortably more than once a week had considerably higher odds of central obesity than those who did not have this problem and those who had experienced it less than once a week in the last month $(P=0.001$ and 0.003$)$. The prevalence of central obesity in participants who have experienced bad dreams was significantly higher than in those who had not in the past month $(P=0.040)$. In addition, women in the survey claiming the highest category of subjective sleep quality (very good) obtained higher odds of central obesity than those as "fairly good" $(P<0.001)$. 
Table 3

Cluster logistic regression models explaining central obesity by variables in three clusters

\begin{tabular}{|c|c|c|c|c|}
\hline Predictor Variable ${ }^{a}$ & $\mathrm{OR}^{\mathrm{b}}(95 \% \mathrm{Cl})$ & $\mathbf{P}$ & $\begin{array}{l}\text { Nagelkerke } \\
\mathrm{R}^{2 \mathrm{c}}\end{array}$ & $\begin{array}{l}\text { Independent } \\
\text { Contribution(\%) }\end{array}$ \\
\hline \multicolumn{5}{|l|}{ Cluster 1} \\
\hline Age group(years)(15-25) & Reference & & & \\
\hline $26-35$ & $\begin{array}{l}2.04(1.40- \\
2.98)\end{array}$ & $\begin{array}{l}<.001 \\
0.001\end{array}$ & & \\
\hline $36-45$ & $\begin{array}{l}2.47(1.65- \\
3.68)\end{array}$ & $\begin{array}{l}<.001 \\
0.00\end{array}$ & & \\
\hline $46-49$ & $\begin{array}{l}2.58(1.59- \\
4.19)\end{array}$ & $\begin{array}{l}< \\
0.001\end{array}$ & & \\
\hline Marital status(Unmarried) & Reference & & & \\
\hline Married & $\begin{array}{l}1.90(1.31- \\
2.74)\end{array}$ & 0.001 & & \\
\hline $\begin{array}{l}\text { Educational level(Primary school } \\
\text { or lower) }\end{array}$ & Reference & & & \\
\hline High school or above & $\begin{array}{l}0.48(0.30- \\
0.77)\end{array}$ & 0.002 & & \\
\hline Occupational status(Employed) & Reference & & & \\
\hline Unemployed & $\begin{array}{l}1.40(1.11- \\
1.77)\end{array}$ & 0.004 & & \\
\hline Total & & & 0.074 & $73.3 \%$ \\
\hline \multicolumn{5}{|l|}{ Cluster 2} \\
\hline Hypertension, yes vs. no & $\begin{array}{l}4.17(1.78- \\
9.75)\end{array}$ & 0.001 & & \\
\hline Diabetes mellitus, yes vs. no & $\begin{array}{l}5.32(1.07- \\
26.45)\end{array}$ & 0.041 & & \\
\hline
\end{tabular}

Note: The forward stepwise method was used in the logistic regression analysis.

a Only variables with $\mathrm{P} \leq 0.05$ were included in the model.

b For age group, marital status, educational level, occupational status, hypertension, diabetes mellitus, hospitalization in the last year, and sleep quality domain scores, odd ratios per standard deviation increase were presented.

${ }^{\mathrm{c}}$ Nagelkerke $\mathrm{R}^{2}$ in this study is the variance of the dependent variable (central obesity), which could be explained by variables in three clusters included in the regression model. 


\begin{tabular}{|c|c|c|c|c|}
\hline Predictor Variable ${ }^{a}$ & $\mathrm{OR}^{\mathrm{b}}(95 \% \mathrm{Cl})$ & $\mathbf{P}$ & $\begin{array}{l}\text { Nagelkerke } \\
\mathrm{R}^{2 \mathrm{c}}\end{array}$ & $\begin{array}{l}\text { Independent } \\
\text { Contribution(\%) }\end{array}$ \\
\hline $\begin{array}{l}\text { Hospitalization in the last year, } \\
\text { yes vs. no }\end{array}$ & $\begin{array}{l}1.88(1.33- \\
2.65)\end{array}$ & $<.001$ & & \\
\hline Total & & & 0.091 & $16.8 \%$ \\
\hline \multicolumn{5}{|l|}{ Cluster 3} \\
\hline Global PSQI score, > 7 vs. $\leq 7$ & $\begin{array}{l}2.20(1.28- \\
3.78)\end{array}$ & 0.004 & & \\
\hline Subjective sleep quality & $\begin{array}{l}0.81(0.73- \\
0.90)\end{array}$ & $<.001$ & & \\
\hline Sleep disturbance & $\begin{array}{l}1.11(1.01- \\
1.22)\end{array}$ & 0.042 & & \\
\hline Total & & & 0.101 & $9.9 \%$ \\
\hline \multicolumn{5}{|c|}{ Note: The forward stepwise method was used in the logistic regression analysis. } \\
\hline \multicolumn{5}{|c|}{ a Only variables with $\mathrm{P} \leq 0.05$ were included in the model. } \\
\hline \multicolumn{5}{|c|}{$\begin{array}{l}{ }^{b} \text { For age group, marital status, educational level, occupational status, hypertension, diabetes mellitus } \\
\text { hospitalization in the last year, and sleep quality domain scores, odd ratios per standard deviation } \\
\text { increase were presented. }\end{array}$} \\
\hline $\begin{array}{l}{ }^{c} \text { Nagelkerke } R^{2} \text { in this study is } \\
\text { be explained by variables in thr }\end{array}$ & $\begin{array}{l}\text { iance of the } \\
\text { ters include }\end{array}$ & $\begin{array}{l}\text { endent } \\
\text { he regr }\end{array}$ & $\begin{array}{l}\text { riable (centı } \\
\text { sion model. }\end{array}$ & obesity), which could \\
\hline
\end{tabular}

\section{Discussion}

The purpose of this study was to explore the correlation between sleep quality and central obesity and to evaluate the independent contribution of sleep quality to central obesity among Chinese reproductiveaged women. Our analyses revealed that poor sleep quality was significantly associated with central obesity. The odds of central obesity were significantly positive with the sleep disturbance scores and negatively related with subjective sleep quality scores. In addition, the symptoms of sleep disturbances (inability to breathe comfortably and having bad dreams) were associated with central obesity. The independent contribution of sleep quality to central obesity was smaller than those of sociodemographic and health-related variables.

Our study identified sleep quality as a significant independent determinant of central obesity among Chinese reproductive-aged women. Poor sleep quality was significantly associated with central obesity after adjusting for variables in Clusters 1 and 2. A population-based German study, including 753 adults aged 35-65 years, indicated that poor sleep quality was associated with obesity and high body fat mass 
[9]. In an earlier study among African Americans, Bidulescu reported that the global sleep quality score was only related to obesity in females [26].

Several potential mechanisms accounting for the link of poor sleep quality and central obesity might be that reduced sleep quality might contribute to changes in metabolism, hormone secretion, and appetite regulation. These changes could lead to energy dysregulation that result in obesity. For instance, the secretion of ghrelin and leptin and neuronal activity in response to food stimuli are proved to be regulated by sleep restriction and act on appetite regulation, thus affecting food choice and calorie intake $[4,27]$. Besides, poor sleep quality can be linked to sleepiness and fatigue. It may lead to reduced daytime physical activity indirectly, thus encouraging weight gain and abdominal fat accumulation [28, 29]. The reduction in physical activity seems to be a plausible pathway by which poor sleep quality could result in obesity. Overall, this kind of sleep-induced disbalance in energy intake and expenditure might play a crucial part in weight changes. The relations observed between sleep quality and central obesity have not been fully understood and the mechanisms of these possibilities are needed to be substantiated in future longitudinal or follow-up studies.

In the current study, we found that women with higher scores in the sleep disturbance component had a higher prevalence of central obesity after controlling for sociodemographic (Cluster 1 ) and health-related (Cluster 2) factors. These results were also observed in a study conducted on 796 Taiwanese male police officers [30]. Similarly, another study reported that to some extent, females with elevated sleep disturbance scores had greater odds of abdominal obesity than those without [6]. Furthermore, we found that among the symptoms of sleep disturbances, the inability to breathe comfortably and having bad dreams showed significant associations with central obesity. As such, women with sleep disturbances should be screened for central obesity in an effort to prevent obesity-related chronic diseases. However, this tends to be problematic since the sleep-obesity link might be two-way. Although poor sleep could predispose one to obesity by altering energy regulatory hormones and behaviors, obesity is also likely to exacerbate sleep problems via co-occurring sleep-related breathing disorders [31]. Thus, our findings may be a support for improving screening methods for unrecognized sleep-related breathing disorders in groups with complaints of sleep disturbance (inability to breathe comfortably). In addition, stress-induced systemic inflammation might be a biological mechanism linking sleep disturbances, central obesity, and other chronic diseases [32]. Women in reproductive age (15-49 years old), might face multiple pressures from work, family, economy, and society. The presence of sleep disturbances in this population group might be caused by stress, while at the same time, sleep disturbances could also bring about stress. This vicious circle would undoubtedly seriously affect women's health. Therefore, good sleep quality is critical to the holistic health, including maintaining a healthy body shape for women.

Interestingly, we found that women reporting the highest category of subjective sleep quality (very good) had higher odds of central obesity than women reporting it as "fairly good" (after controlling for variables in Clusters 1 and 2). A U-shaped correlation of total sleep duration with BMI have been reported in some prior studies, especially in women $[7,8]$. One possible explanation for this finding is that individuals who have very good sleep quality might have longer sleep durations and thus have relatively less time during 
the day to engage in physical activity, which could serve as an indirect mechanism linking very good sleep quality with obesity. In our study, there was certainly a slight difference in average sleep duration between women who reported "very good" and "quite good" subjective sleep quality categories ( $7.8 \mathrm{~h}$ per night versus 7.6 per night; $P<0.001)$. More studies are necessary to elucidate potential mediators of the relationship.

We also found that the independent contribution of sleep quality to central obesity was smaller than those of sociodemographic and health-related factors. Obesity is the result of fat accumulation for a period of time. Yet, the PSQI reflects sleep quality for the last month, which may be a relatively short period for assessing the effect of sleep quality on central obesity. It would, therefore, be worthwhile to consider longer follow-up to further assess the impact of sleep quality on central obesity. Although the concrete mechanisms linking poor sleep quality and central obesity are not fully clear, the results do suggest that sleep quality is correlated with WC in Chinese reproductive-aged women. In light of central obesity which has been proved to be fairly relevant to chronic and metabolic diseases, reasonable sleep might be of benefit in the prevention and intervention of obesity.

Among the three clusters, the first cluster made the greatest independent contribution to central obesity and age was significantly associated with central obesity. The previous study has found that aging is related to raised adiposity in white adipose tissues as well as thermogenic impairment in brown adipose tissue, which may increase the incidence of obesity [33]. Besides, in females, estrogen receptor (ER) a was proven to have a protective role in maintaining metabolic homeostasis [34]. Earlier studies have shown that there was an inverse link between age and gene expression for ERa and the ratio of ERa to ERß in female abdominal subcutaneous fatty tissue [35]. Some researchers have found that the prevalence of obesity varies not only by age but also by income and educational levels [36, 37]. Consistently, in our study, unemployed participants had higher odds of central obesity than those employed ones; we also observed that compared with women who had primary school or lower education, those who had an educational level of high school or above had lower odds of central obesity. It might be due to cognitive skills and health literacy varying among individuals in different educational levels. In order to prevent central obesity of reproductive-aged women and promote their health, further studies are necessary to clarify the specific mechanisms between the relevant factors and central obesity among this population group.

\section{Limitations}

Several limitations of this study should be noted. First, due to the cross-sectional nature of the study, the causality of sleep quality and central obesity might not be elucidated; longitudinal and intervention studies may provide a better understanding about it. Second, we did not measure hormones or laboratory indexes (e.g., ghrelin, leptin, insulin resistance, or sympathoadrenal activity), which might be the mediator between sleep quality and central obesity.

\section{Conclusion}


Our findings demonstrated that the independent effect of sleep quality to central obesity was significant among Chinese reproductive-aged women. Poor sleep quality and the components of subjective sleep quality and sleep disturbance (inability to breathe comfortably and having bad dreams) were associated with central obesity. Furthermore, we found that the independent contribution of sleep quality to central obesity was smaller than those of sociodemographic and health-related variables. It may be a support for the discovery of novel strategies to prevent central obesity and promote health of this population group.

\section{Abbreviations}

PSQI: the Pittsburgh Sleep Quality Index; Cl: confidence interval; OR: Odds Ratio; MetS: metabolic syndrome; WC: waist circumference; SAHS: sleep apnea hypopnea syndrome; ER: estrogen receptor

\section{Declarations}

\section{Acknowledgements}

The authors specially acknowledge the staffs who helped collecting data and coordinating in this survey and all participants who took part in this survey.

\section{Funding}

This work was supported by the National Natural Science Foundation of China [grant number 81872584]; the Henan key R\&D and promotion program [grant number 2019510].

\section{Author contributions}

BBL, GZZ, and PXW designed the study. BBL and PXW carried out the data analysis. All authors participated in interpretation of the data results. BBL, NL and PXW conducted the data analyses. $B B L, N L$, $\mathrm{BL}$, and PXW draft the manuscript. DHG, BL, YL, LLH, XXW, and ZZS reviewed and checked the important content of the paper. BBL, NL, BL, GZZ, and PXW finalized the manuscript based on the comments of all authors. All authors approved this submission.

\section{Ethics approval and consent to participate}

Written informed consent was obtained from each study participant. The People's Hospital of Longhua.Shenzhen Medical Ethics Committee approved the study (2917055). 
Availability of data and materials

The data supporting our findings are kept in confidentiality and available from the corresponding author on reasonable request.

Competing interests

The authors declare that they have no competing interests.

\section{References}

1. Ortega FB, Sui X, Lavie CJ, Blair SN: Body Mass Index, the Most Widely Used But Also Widely Criticized Index: Would a Criterion Standard Measure of Total Body Fat Be a Better Predictor of Cardiovascular Disease Mortality? Mayo Clinic proceedings 2016, 91(4):443-455.

2. Flegal KM, Graubard BI, Williamson DF, Gail MH: Cause-specific excess deaths associated with underweight, overweight, and obesity. JAMA 2007, 298(17):2028-2037.

3. Despres JP: Is visceral obesity the cause of the metabolic syndrome? Annals of medicine 2006, 38(1):52-63.

4. Spiegel, Karine: Brief Communication: Sleep Curtailment in Healthy Young Men Is Associated with Decreased Leptin Levels, Elevated Ghrelin Levels, and Increased Hunger and Appetite. Annals of Internal Medicine 2004, 141(11):846.

5. Pejovic S, Vgontzas AN, Basta M, Tsaoussoglou M, Zoumakis E, Vgontzas A, Bixler EO, Chrousos GP: Leptin and hunger levels in young healthy adults after one night of sleep loss. J Sleep Res 2010, 19(4):552-558.

6. Liu RQ, Qian Z, Wang SQ, Vaughn MG, Geiger SD, Xian H, Lin S, Paul G, Zeng XW, Yang BY et al: SexSpecific Difference in the Association Between Poor Sleep Quality and Abdominal Obesity in Rural Chinese: A Large Population-Based Study. Journal of clinical sleep medicine : JCSM : official publication of the American Academy of Sleep Medicine 2017, 13(4):565-574.

7. Buscemi D, Kumar A, Nugent R, Nugent K: Short sleep times predict obesity in internal medicine clinic patients. J Clin Sleep Med 2007, 3(7):681-688.

8. Sivertsen B, Pallesen S, Sand L, Hysing M: Sleep and body mass index in adolescence: results from a large population-based study of Norwegian adolescents aged 16 to 19 years. BMC Pediatr 2014, 14:204.

9. Rahe C, Czira ME, Teismann H, Berger K: Associations between poor sleep quality and different measures of obesity. Sleep medicine 2015, 16(10):1225-1228.

10. Vargas PA, Flores M, Robles E: Sleep quality and body mass index in college students: the role of sleep disturbances. Journal of American college health : J of ACH 2014, 62(8):534-541. 
11. Li R, Shi L, Jia J, Li Y, Yang Q, Ruan Y, Chen R, Kan H: Differentiating the associations of waist circumference and body mass index with cardiovascular disease risk in a Chinese population. Asia Pac J Public Health 2015, 27(2):NP457-467.

12. Huang $\mathrm{LH}$, Liao YL, Hsu CH: Waist circumference is a better predictor than body mass index of insulin resistance in type 2 diabetes. Obes Res Clin Pract 2012, 6(4):e263-346.

13. Buzzetti R, Eloi JC, Epifanio M, de Gonçalves MM, Pellicioli A, Vieira PFG, Dias HB, Bruscato N, Soder RB, Santana JCB et al: Quantification of Abdominal Fat in Obese and Healthy Adolescents Using 3 Tesla Magnetic Resonance Imaging and Free Software for Image Analysis. Plos One 2017, 12(1): $\mathrm{e} 0167625$.

14. Du P, Zhang B, Wang HJ, Qi SF, Mi YJ, Yao JC, Liu DW, Tian QB: The prevalence and secular trends of abdominal obesity among Chinese adults, 1993-2011. Annals of epidemiology 2015, 25(10):797799.

15. Zhai Y, Fang HY, Yu WT, Yu DM, Zhao LY, Liang XF, Zhao WH: Changes in Waist Circumference and Abdominal Obesity among Chinese Adults over a Ten-year Period. Biomed Environ Sci 2017, 30(5):315-322.

16. Hung $\mathrm{H}$, Yang $\mathrm{Y}, \mathrm{Ou} \mathrm{H}, \mathrm{Wu} J$, Lu F, Chang C: The association between self-reported sleep quality and overweight in a Chinese population. Obesity 2013, 21(3):486-492.

17. Buysse DJ, Reynolds CF, Monk TH, Berman SR, Kupfer DJ: The Pittsburgh Sleep Quality Index: a new instrument for psychiatric practice and research. Psychiatry Res 1989, 28(2):193-213.

18. Backhaus J, Junghanns K, Broocks A, Riemann D, Hohagen F: Test-retest reliability and validity of the Pittsburgh Sleep Quality Index in primary insomnia. J Psychosom Res 2002, 53(3):737-740.

19. Tsai PS, Wang SY, Wang MY, Su CT, Yang TT, Huang CJ, Fang SC: Psychometric evaluation of the Chinese version of the Pittsburgh Sleep Quality Index (CPSQI) in primary insomnia and control subjects. Quality of life research : an international journal of quality of life aspects of treatment, care and rehabilitation 2005, 14(8):1943-1952.

20. Mollayeva T, Thurairajah P, Burton K, Mollayeva S, Shapiro CM, Colantonio A: The Pittsburgh sleep quality index as a screening tool for sleep dysfunction in clinical and non-clinical samples: A systematic review and meta-analysis. Sleep Medicine Reviews 2016, 25:52-73.

21. Liu XC, Tang MQ, Hu L, Wang AZ, Wu HX, Zhao GF, Gao CN, Li WS: Reliability and validity of the pittsburgh sleep quality index. Chinese Journal of Psychiatry 1996, 29(2):103-107.

22. Rossi AP, Bianchi L, Volpato S, Bandinelli S, Guralnik J, Zamboni M, Ferrucci L: Dynapenic Abdominal Obesity as a Predictor of Worsening Disability, Hospitalization, and Mortality in Older Adults: Results From the InCHIANTI Study. The journals of gerontology Series A, Biological sciences and medical sciences 2017, 72(8):1098-1104.

23. Wu Y, Huxley R, Li L, Anna V, Xie G, Yao C, Woodward M, Li X, Chalmers J, Gao R et al: Prevalence, awareness, treatment, and control of hypertension in China: data from the China National Nutrition and Health Survey 2002. Circulation 2008, 118(25):2679-2686. 
24. Wang XX, Chen ZB, Chen XJ, Huang LL, Song XY, Wu X, Fu LY, Wang PX: Functional status and annual hospitalization in multimorbid and non-multimorbid older adults: a cross-sectional study in Southern China. Health and quality of life outcomes 2018, 16(1):33.

25. Nagelkerke NJD: A Note on a General Definition of the Coefficient of Determination. Biometrika 1991, 78(3):691-692.

26. Bidulescu A, Din-Dzietham R, Coverson DL, Chen Z, Meng YX, Buxbaum SG, Gibbons GH, Welch VL: Interaction of sleep quality and psychosocial stress on obesity in African Americans: the Cardiovascular Health Epidemiology Study (CHES). BMC Public Health 2010, 10:581.

27. St-Onge MP, McReynolds A, Trivedi ZB, Roberts AL, Sy M, Hirsch J: Sleep restriction leads to increased activation of brain regions sensitive to food stimuli. The American journal of clinical nutrition 2012, 95(4):818-824.

28. Magee CA, Reddy P, Robinson L, McGregor A: Sleep quality subtypes and obesity. Health psychology : official journal of the Division of Health Psychology, American Psychological Association 2016, 35(12):1289-1297.

29. Kahlhofer J, Karschin J, Breusing N, Bosy-Westphal A: Relationship between actigraphy-assessed sleep quality and fat mass in college students. Obesity 2016, 24(2):335-341.

30. Chang JH, Huang PT, Lin YK, Lin CE, Lin CM, Shieh YH, Lin YC: Association between sleep duration and sleep quality, and metabolic syndrome in Taiwanese police officers. International journal of occupational medicine and environmental health 2015, 28(6):1011-1023.

31. Seetho IW, Wilding JP: Screening for obstructive sleep apnoea in obesity and diabetes-potential for future approaches. European journal of clinical investigation 2013, 43(6):640-655.

32. Prather AA, Puterman E, Epel ES, Dhabhar FS: Poor sleep quality potentiates stress-induced cytokine reactivity in postmenopausal women with high visceral abdominal adiposity. Brain Behav Immun 2014, 35:155-162.

33. Lin L, Saha PK, Ma X, Henshaw IO, Shao L, Chang BHJ, Buras ED, Tong Q, Chan L, McGuinness OP et al: Ablation of ghrelin receptor reduces adiposity and improves insulin sensitivity during aging by regulating fat metabolism in white and brown adipose tissues. Aging Cell 2011, 10(6):996-1010.

34. Hevener AL, Clegg DJ, Mauvais-Jarvis F: Impaired estrogen receptor action in the pathogenesis of the metabolic syndrome. Mol Cell Endocrinol 2015, 418 Pt 3:306-321.

35. Park YM, Erickson C, Bessesen D, Van Pelt RE, Cox-York K: Age- and menopause-related differences in subcutaneous adipose tissue estrogen receptor mRNA expression. Steroids 2017, 121:17-21.

36. Ogden CL, Fakhouri TH, Carroll MD, Hales CM, Fryar CD, Li X, Freedman DS: Prevalence of Obesity Among Adults, by Household Income and Education - United States, 2011-2014. MMWR Morb Mortal Wkly Rep 2017, 66(50):1369-1373.

37. Kim YJ: The long-run effect of education on obesity in the US. Economics and human biology 2016, 21:100-109.

\section{Figures}




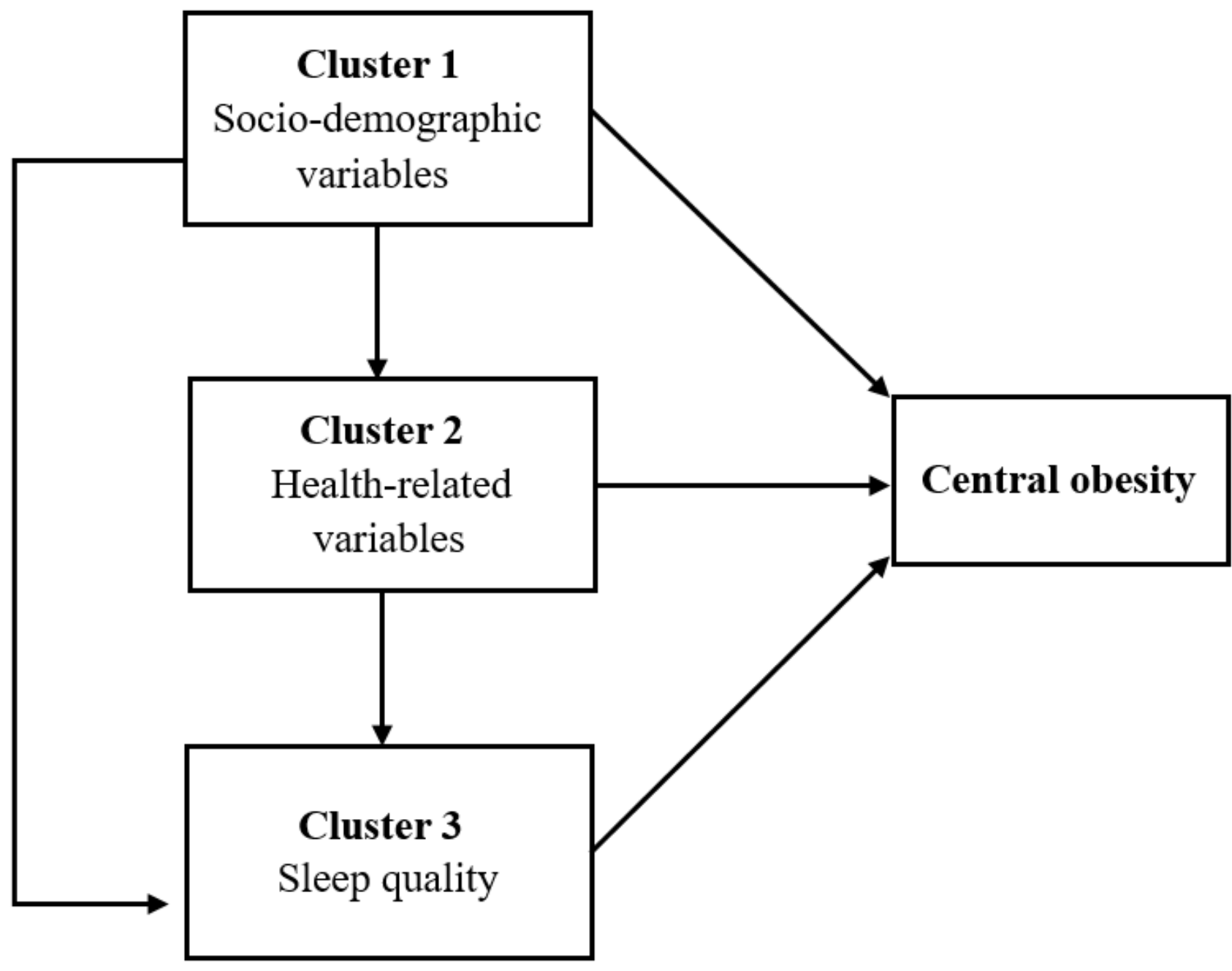

Dependent Variables

\section{Independent Variables}

Figure 1

The clustered multiple logistic regression model and multi-directional associations (the direction of the impact was indicated by the direction of the arrows) 

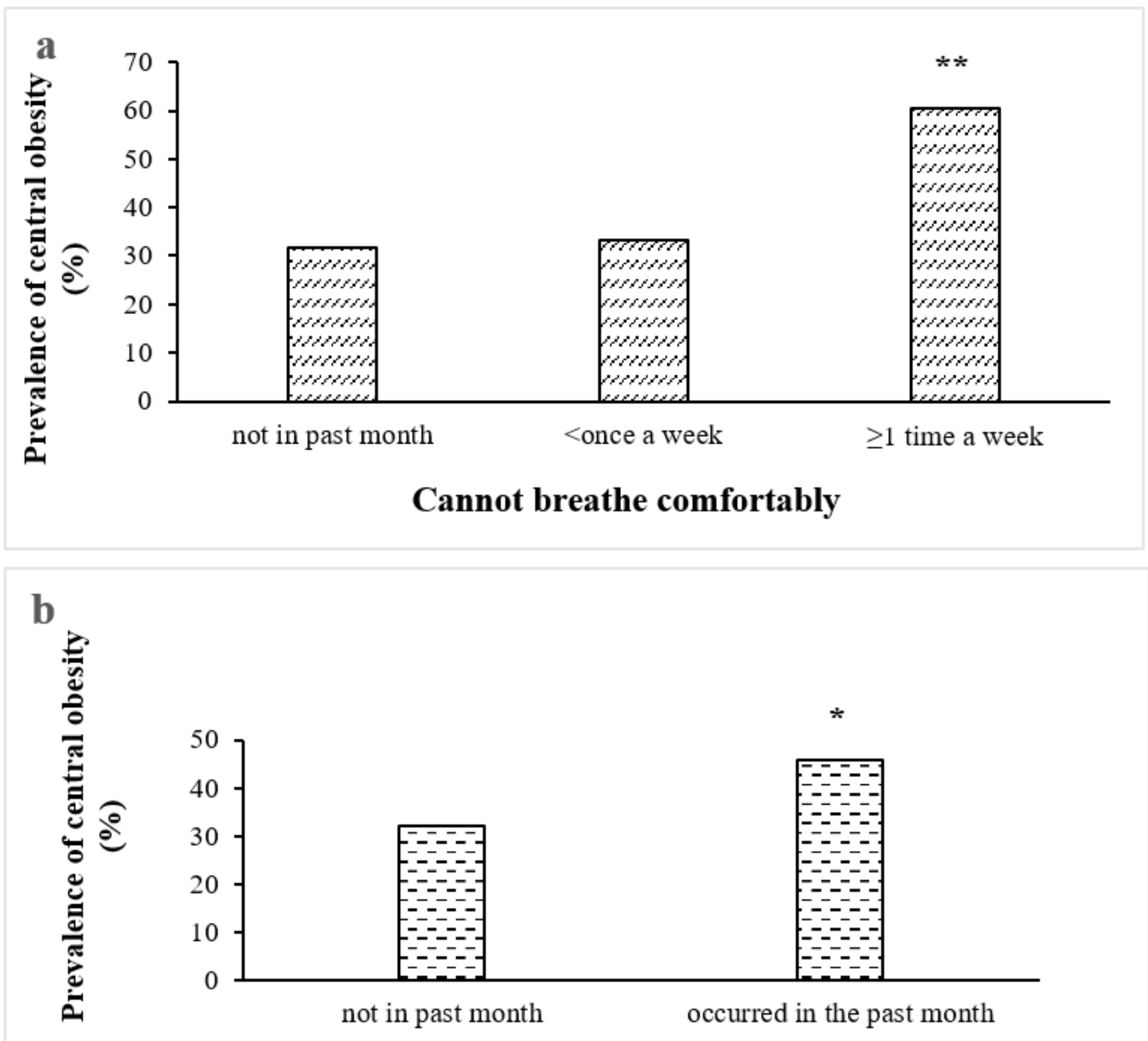

Have bad dreams

Figure 2

Comparisons of the prevalence of central obesity in participants with sleep disturbances. ${ }^{\star *} \mathrm{P}<0.01$, ${ }^{*} \mathrm{P}<0.05$, after adjusting for sociodemographic variables in Cluster 1 and health-related variables in Cluster 2; (a) $\geq 1$ time a week compared with not in past month, $\mathrm{P}=0.001 ; \geq 1$ time a week compared with $<$ once a week, $\mathrm{P}=0.003$; (b) occurred in the past month compared with not in past month, $\mathrm{P}=0.040$. 